\title{
Violência sistêmica e educação
}

\section{Systemic violence and education}

\section{Violencia sistémica y educación}

\author{
Pedro Goergen" \\ Professor titular na Universidade de Sorocaba
}

Resumo: Com este artigo questiono se a educação, quando atrelada ao sistema econômico neoliberal, se torna ou não corresponsável pela disseminação sistêmica da violência. Assumo a tese de que a educação, enquanto processo de integração dos indivíduos nesse sistema, está atrelada à ideia de preparo dos jovens não só para o mundo violento, mas também à habilitação para o manejo e o exercício da violência como estratégia de sobrevivência e afirmação pessoal. A urgência está em defender a tarefa formativa, humanista da educação, ao mesmo tempo em que necessita preparar as novas gerações para o mundo real, com todos os traços anti-humanistas que lhe são inerentes. De início, faço observações sobre violência com base em alguns autores clássicos; a seguir, comento o tema na perspectiva da relação entre as pessoas e os sistemas econômicos, destacando o domínio da lógica do capital sobre todas as relações sociais e esferas da vida. Concluindo, tento mostrar que esse tema se encontra no centro das preocupações e debates a respeito dos caminhos da educação no contexto da realidade econômica regida pelos princípios político-econômicos do neoliberalismo.

Palavras-chave: Educação. Violência sistêmica. Formação humanista.

Abstract: In this text, I ask if education, when connected to the neoliberal economic system, becomes co-responsible for the systemic growth of violence. I accept the thesis that education while the process of integration of individuals into this system is connected to the idea of preparing young people not only for the violent world, but also habilitate for the management and exercise of violence as a strategy for survival and personal affirmation. The urgency is defend the

Pós-Doutor pela Universidade de Bochum e pelo Instituto Max Planck da Alemanha; Doutor em Filosofia pela Ludwig Maximilians Universität München. 
formative and humanist task of education, at the same time that it needs to prepare new generations for the real world, with all anti-humanistic aspects inherent to it. At first, I make considerations about violence based on some classical philosophers; after that, I remark on the subject from the perspective of the relationship between people and economic systems, highlighting the domain of the logic of capital over all social relations and spheres of life. Concluding, I try to demonstrate that this theme found at the center of the concerns and debates about the direction of education in context of economic reality governed by the political/economic principles of neoliberalism.

Keywords: Education. Systemic violence. Humanistic education.

Resumen: En este artigo cuestiono si la educación, cuando se vincula al sistema económico neoliberal, se vuelve corresponsable por la diseminación sistémica de la violencia. Asumo la tesis que la educación, como proceso de integración de los individuos en este sistema, está vinculada a la idea de preparación de los jóvenes no sólo para el mundo violento, sino también a la habilitación para el manejo y el ejercicio de la violencia como estrategia de supervivencia y afirmación personal. La urgencia está en defender la tarea formativa y humanista de la educación al mismo tiempo que necesita preparar a las nuevas generaciones para el mundo real, con todos los rasgos anti humanistas que le son inherentes. Al principio hago observaciones sobre la violencia basada en algunos pensadores clásicos; a continuación, comento el tema en la perspectiva de la relación entre las personas y los sistemas económicos, destacando el dominio de la lógica del capital sobre todas las relaciones sociales y esferas de la vida. Concluyendo, intento mostrar que este tema se encuentra en el centro de las preocupaciones y debates acerca de los caminos de la educación en el contexto de la realidad económica regida por los principios político/económicos del neoliberalismo.

Palabras clave: Educación. Violencia sistémica. Formación humanista.

\section{INTRODUÇÃO}

A violência é, sem dúvida, uma das preocupações centrais da sociedade contemporânea. Ela se apresenta das mais variadas formas, desde 
as sutis e sorrateiras violências midiática, ideológica, econômica e cultural, até as mais brutais expressões de violência física, da exclusão econômica, da perseguição política, de guerras étnicas e religiosas e dos assassinatos por motivos fúteis. As estatísticas mostram índices cada dia mais alarmantes e assustadores ao ponto de ninguém mais se sentir seguro, seja nos grandes centros urbanos, seja nos mais recônditos e pacatos vilarejos do interior. Por ser um fenômeno mundial e afetar todas as pessoas, estejam elas onde estiverem, a violência se tornou a preocupação central da vida de todos.

Pode-se dizer, sem risco de errar, que a violência é hoje o tema mais comentado e discutido, tanto nas conversas informais, quanto na mídia e na academia. As razões disso parecem óbvias, ainda que contraditórias: de um lado, fala-se, discute-se, escreve-se e transmitem-se tantas imagens sobre a violência que ela parece ser efetivamente a maior preocupação, o maior temor da humanidade; de outro, a violência, embora chocante, torna-se cada vez mais incontornável, suave, colorida, banal e espetacularizada com o grande aporte da tecnologia, transformando a tecno/violência em herói e bandido da sociedade contemporânea. $\bigcirc$ que ainda choca é a violência grotesca, direta, física; nos importamos menos ou somos mais tolerantes com a violência velada, sistêmica, embora talvez esta não seja menos letal. É desse sentido de violência que trata o presente artigo.

Desde logo, é preciso esclarecer que a violência é usada como uma estratégia de sobrevivência por todos os seres vivos deste planeta. Esse ponto de partida é muito relevante para que não se incorra numa visão falsa e inocente a respeito dos seres vivos e dos seres humanos em particular. Dessa convicção decorrem algumas consequências para a discussão dessa problemática. Primeiro, os seres humanos formam um grupo de seres que buscaram e buscam desenvolver estratégias de vida em sociedade, ou seja, procuram resolver seus conflitos na luta pela existência, sem o uso da violência; segundo, esse objetivo não foi alcançado até hoje e continua sendo, senão a maior, ao menos uma das maiores preocupações da humanidade até hoje; terceiro, é pouco relevante discutir se hoje a violência é menor ou maior que no passado; quarto, é importante considerar que, com o avanço da ciência e tecnologia, o exercício da violência se tornou mais eficiente e letal; quinto, que 
a violência se dissemina pela sociedade como um todo, internalizado no sistema socioeconômico como estratégia de poder e domínio; por último, a violência sistêmica passa a ser internalizada pelos próprios indivíduos, tornando-a reconhecida como estratégia de desempenho e sucesso.

O objetivo das considerações a seguir é, portanto, destacar a natureza sistêmica da violência e trazer essa nova realidade para o campo da educação. A pergunta é se a educação, na medida em que se atrela ao sistema, tornase ou não corresponsável pela disseminação sistêmica da violência. Nesse sentido, é importante alertar que reconhecer a realidade do nosso tempo como um ponto de partida para a elaboração da teoria e da prática educacionais não significa submeter-se a ela, não significa resignar, conformar-se aos fatos. Ao contrário, o reconhecimento da realidade deve ser o incontornável ponto de partida para a mudança e a transformação.

De início, faço algumas observações mais gerais sobre violência com base em alguns autores clássicos; a seguir, comento o tema na perspectiva da relação entre as pessoas e os sistemas econômicos, inspirando-me nas ideias de Pierre Dardot e Christian Laval, expostas no recente livro A nova razão do mundo (2016), em que destacam o domínio da lógica do capital sobre todas as relações sociais e esferas da vida. Concluindo, mostro que esse tema se encontra no centro das preocupações e debates a respeito dos caminhos da educação no contexto da realidade econômica regida pelos princípios políticoeconômicos do neoliberalismo.

\section{I}

Hoje a violência afeta também os setores dominantes da sociedade que antes se sentiam mais seguros. Enquanto restrita às classes mais humildes, a elite pouco se importava com a violência. Não se importava não porque não era violenta, mas porque tinha condições de preservar-se, ela mesma, da violência. Numa perspectiva antropológica, pode-se dizer que o ser humano é um ser violento por natureza, visto que a violência faz parte da estratégia 
de sobrevivência, da luta pelo mesmo espaço, pelo mesmo alimento, pelos mesmos parceiros, própria do mundo animal do qual o ser humano faz parte.

A grande diferença entre a violência humana e a violência animal decorre precisamente da constituição da própria humanidade que faz da moral, ou seja, da convivência, a estratégia de sua sobrevivência que é a origem e o fundamento da moral. A moral se fixa numa estrutura de normas e preceitos éticos, vinculantes para todos. Em condições históricas e culturais variáveis, essa estrutura normativa também assume características distintas. Nesse sentido, o ser humano imoral se aproxima do mundo animal, com a diferença de que a violência humana muda historicamente, tanto em termos da ação quanto do controle.

Em tempos de ciência e tecnologia, a violência alcançou tal grau de eficiência que seu controle se torna difícil, ameaçando a destruição de agredido e agressor. Nietzsche (2005, p. 70) argumenta que a construção das relações interpessoais provavelmente tenha sua origem no mundo animal, na busca de superação da agressividade mediante uma maior horizontalidade e igualdade. "Com base nisso", assim se lê em Humano, demasiado humano: "se constrói [...] a mais antiga aliança, cujo sentido é defender-se e eliminar conjuntamente um desprazer ameaçador em proveito de cada indivíduo [...]". Como é sabido, Nietzsche é um crítico severo da moral grega e de toda a tradição religiosa e racional posterior. Segundo ele, a visão socrático-platônica, arruinou o espírito dionisíaco da tragédia grega, substituindo-a por uma visão apolínea, condizente com a imagem de um ser humano harmônico, distante das pulsões instintivas incontroladas da animalidade. Consagra-se, assim, o espírito, a essência, a harmonia e nega-se o instinto, a pulsão, a corporeidade.

A polêmica postura de Nietzsche contra essa tradição coloca em tela de juízo o conceito de violência humana, trazendo à tona perguntas como: quando se fala em violência humana, por que se qualifica, nesse caso, o termo violência com o adjetivo 'humana'? Animais quando se agridem ou agridem humanos praticam violência? A luta pela sobrevivência mediante o uso da violência é algo conatural aos seres humanos e aos animais? A violência humana é violência apenas quando agride outros seres humanos? Em tempos pós-teológicos e pós-metafísicos quem confere ao ser humano o direito do 
exercício do poder (da violência) sobre os demais seres? Quem confere ao Estado o poder despótico, panóptico, quase absoluto de violência sobre as pessoas?

São questões difíceis de serem respondidas numa perspectiva de horizontalidade, ou seja, sem uma instância superior fundante; por outro lado, se abandonarmos a horizontalidade e recorrermos à verticalidade metafísicoteológica ou mesmo estatal, também abandonamos a grande revolução moderna da autonomia humana. A autonomia alcançada transferiu, aparentemente em definitivo, do céu para a terra, a responsabilidade pelo respeito e não agressão entre humanos e entre estes e a natureza. Em outras palavras, os seres humanos introduziram uma forma de convivência que denominamos moral, ou seja, de respeito mútuo em razão da condição humana comum. Mas quem disse que os humanos não encontrariam novas formas de verticalidade pós-teológicas e pósmetafísicas de exercício de poder e violência? $\bigcirc$ Estado, seja na perspectiva de Hobbes do necessário Leviatan (2006), seja da volonté générale em Rousseau (1989), ou mesmo da democracia contemporânea, tornou-se a nova forma de controle, do poder e da violência. Hoje essa tradição entra em crise na medida em que, além do Estado, inclusive sobrepondo-se a ele, perfilou-se, especialmente nas últimas décadas, uma nova instância de poder, que é o sistema econômico-mercadológico.

Desde o ponto de vista histórico, a violência humana só é violência em sentido moral porque ofende a convivência pacífica entre seres humanos de direitos, incluindo, mais recentemente, o direito ao meio ambiente, enquanto condição indireta de sobrevivência do humano. A relação entre violência e ética se encontra ancorada na tradição ocidental, na Ética a Nicômaco de Aristóteles, a qual abriu um novo cenário, distinto da mitologia antiga e do engenhoso idealismo platônico. Essa metafísica serviu de inspiração estrutural à teologia agostiniana, a partir do Séc. IV d.C., deixando na saudade a Igreja Primitiva, hoje novo sonho de muitos fiéis. O retorno de Aristóteles, sobrevivente de Alexandria, pela porta dos fundos da Península Ibérica, conduzido pela pena dominicana de Tomás de Aquino, preparou o caminho para a suposta autonomia racional, com seguro fundamento no subjetivismo continental 
de Descartes e no empirismo insular de Locke e Hume, tão magistralmente cotejados e equilibrados por Kant, na sua Crítica da Razão Pura (1985).

Logo na sequência, o filósofo alemão completou seu sistema com a Crítica da Razão Prática (1984) e a Crítica do Juízo (2008), referentes à ética e à sensibilidade, faces, senão esquecidas, ao menos obnubiladas, ao longo da modernidade. $\bigcirc$ que a narrativa moderna reconhece e valoriza são as conquistas do desenvolvimento da ciência a partir dos Séc. XVI e XVII e no Séc. XIX, com seu complemento tecnológico/prático, que juntos potencializaram a intervenção do homem sobre a natureza e sobre si mesmo. Paulatinamente, o uso do poder se desconectou da luta pela sobrevivência, transformando-se em violência a serviço do poder, do domínio, do acúmulo de riqueza.

Essa mentalidade, ou seja, essa maneira de pensar, de sentir, de ser do homem transformou-se na grande marca de nossa cultura, desde o dia a dia na convivência com o outro, na família ou no trabalho, até os grandes negócios e a economia. A violência se torna a grande marca dos tempos modernos, sobretudo em decorrência do empoderamento do ser humano pela ciência e tecnologia. Como dizem Adorno e Horkheimer (1985, p. 20),

o saber que é poder não conhece nenhuma barreira, nem na escravização da criatura nem na complacência em face aos senhores do mundo. [...] $\bigcirc$ que os homens querem aprender da natureza é como empregá-la para dominar completamente a ela e aos homens. [...] $\bigcirc$ que importa não é aquela satisfação que, para os homens, se chama 'verdade', mas a operation, o procedimento eficaz.

Reconhecendo a plausibilidade desse argumento, vale refletir sobre as consequências dessa realidade para relações sociais nas distintas esferas da vida. No prefácio de A nova razão do mundo, os autores Dardot e Laval (2016) afirmam que

capitalismo é indissociável da história de suas metamorfoses, de seus descarrilamentos, das lutas que o transformam, das estratégias que o renovam. $\bigcirc$ neoliberalismo transformou profundamente o capitalismo, transformando profundamente as sociedades. [...] É um sistema normativo 
que ampliou sua influência ao mundo inteiro, estendendo a lógica do capital a todas as relações sociais e a todas as esferas da vida.

Desde o momento em que essas palavras foram escritas, há quase 10 anos, tal prognóstico não somente vem se confirmando, mas assumindo dimensões cada vez mais graves e preocupantes. $\bigcirc$ caráter sistêmico do capitalismo neoliberal carrega consigo, por assim dizer, toda a sociedade em suas diferentes dimensões, submetendo-as ao seu controle e impedindo qualquer inflexão política, seja na saúde, no governo, na pesquisa e na educação. Isso leva os autores a concluir que "o sistema neoliberal está nos fazendo entrar na era pós-democrática", ou seja, o sistema econômico passa a assumir e determinar os rumos segundo os seus interesses, independente da vontade das pessoas e da sociedade (DARDOT; LAVAL, 2016, p. 8). O demos, supostamente origem e razão da democracia, vem sendo substituído por uma nova razão, a razão do sistema econômico.

As oligarquias burocráticas, o poder das empresas multinacionais e os grandes organismos econômicos e financeiros formam uma rede densa e impenetrável de poder que a si tudo submete. Qualquer tipo de oposição ou divergência se torna difícil, na medida em que a sobrevivência fora do sistema se torna efetivamente impossível. Quem não se submete e não se qualifica para atuar segundo suas diretrizes e exigências é excluído. A concorrência interindividual, a luta de uns contra os outros pelas benesses do sistema e a polarização permanente entre agraciados e desgraçados têm repercussões profundas sobre as novas formas de subjetivação. Os sujeitos aprendem intuitiva ou formalmente que o único caminho de sobrevivência é a integração e a submissão às regras do jogo econômico. $\bigcirc$ pétreo sistema político/econômico que condiciona a socialização condiciona também a subjetivação, de tal modo que não estamos diante somente de uma nova realidade econômica que se impõe, mas também diante de um novo processo de subjetivação que naturaliza e, portanto, não mais questiona essa condição.

Antes de estabelecer a relação entre o sistema econômico capitalista neoliberal e a educação, é importante destacar o papel central do Estado que 
garante e oficializa o novo modelo econômico. Ginsburg (2014), ao tratar do tema 'medo e terror', refere-se a Hobbes, o filósofo que coloca o medo no centro de sua filosofia política. Para Hobbes, o Estado surge de um pacto que nasce do medo, ou seja, da guerra de todos contra todos os seres humanos. Do estado da natureza humana, dominado pelo terror recíproco, nasce o desejo de justiça, a forma de vida em sociedade e sua formulação suprema no Estado. Segundo Ginsburg (2014), o alvo polêmico de Hobbes era a Política de Aristóteles em que o filósofo se propunha a identificar os elementos constituintes da Polis. Para Aristóteles (2012), o homem é, por natureza, um animal político e, portanto, a polis também é um fenômeno natural. Para Hobbes, ao contrário, o estado de natureza não é a socialidade, mas a guerra de todos contra todos.

Segundo o filósofo inglês, a agressão natural gera uma situação generalizada de medo que somente pode ser contornada por um pacto do qual resulta a cives, a cidade, ou seja, o Estado. A reflexão de Hobbes toma como ponto de partida a história da Guerra do Peloponeso e as repercussões da peste que assolou Atenas em 429 a.C. relatadas por Tucídides. As mortes precoces e súbitas levavam as pessoas ao abandono das normas e leis em troca de prazeres imediatos. Ninguém mais se dispunha a fazer sacrifícios por um bem que poderia nunca ser alcançado porque a morte pela peste chegaria antes. Tanto os que se sacrificavam pelo bem quanto os que se entregavam aos prazeres morreriam. Era, então, mais útil aproveitar a vida, gerando um estado de anomia, de dissolução da lei. No Estado de Atenas devastada pela peste, a lei não existia mais. Para Hobbes, no estado de natureza a lei não existe ainda e é do medo da agressividade humana que nasce o Estado. De outro lado, o Estado, o 'deus mortal', gerado pelo medo, incute terror, sujeição e violência, substituindo a religião por uma nova forma de poder secularizado.

Nesta passagem, aqui reproduzida de modo livre, Ginsburg (2014, p. 32) sugere um paralelo entre o papel do Estado em Hobbes e o poder tecnológico que gera temor na contemporaneidade:

Suponhamos que a degradação do ambiente aumente até alcançar níveis até hoje impensáveis. A poluição do ar, da água e da terra acabaria por ameaçar a sobrevivência de muitas espécies animais, inclusive aquela denominada 
homo sapiens sapiens. A essa altura, um controle global, minucioso, sobre o mundo e seus habitantes seria inevitável. A sobrevivência do gênero humano imporia um pacto semelhante àquele postulado por Hobbes: os indivíduos renunciariam às próprias liberdades em favor de um super Estado opressor, de um Leviatã infinitamente mais potente que os passados.

Se o Leviatã de Hobbes, de um lado, foi de alguma maneira profético, de outro, nem em sonho poderia antever que um dia o próprio Estado seria posto a serviço de outro sistema, o econômico, mais poderoso que ele, porém destituído de qualquer sentido de equidade social. Esse é precisamente o grande dilema que se coloca hoje na relação entre o sistema capitalista econômico neoliberal e o Estado. $\bigcirc$ Estado que, embora desde perspectivas distintas, fora pensado por Hobbes e Rousseau, seja na forma de Leviatan ou de um contrato social, como uma estrutura superior que traria proteção e garantia de boa convivência aos cidadãos, ou seja, de justiça social, agrega-se e coloca-se a serviço de um sistema econômico, estreitamente vinculado aos interesses da elite financeira.

Não se trata de assumir uma postura catastrofista com relação ao futuro da humanidade, cujo fim os mais negativistas estão profetizando. $\mathrm{Na}$ verdade, há estudos de longo prazo, como o realizado por Shermer (2015), que argumentam ser possível constatar que estamos progredindo, tanto em termos materiais quanto éticos, numa visão de longo prazo, ou seja, de séculos. Segundo o autor, a humanidade vem se tornando cada vez menos violenta porque conseguiu praticamente eliminar a escravidão e avançou na garantia dos direitos individuais e das minorias. Um exemplo seria a história dos temíveis Vikings, cujo terror atemorizava os povos europeus, mas cujos herdeiros são hoje os pacíficos e amigáveis suecos, dinamarqueses e noruegueses. Trata-se de uma evolução cultural e não biológica, porquanto ocorreu ao longo dos últimos mil anos. Até o início do Séc. XIX, a Suécia era considerada um dos países mais corruptos da Europa e hoje figura como exemplo de respeito, de justiça e igualdade de direitos. A origem dessas mudanças parece estar no desenho da ordem institucional. 
Mas há contra-exemplos. Parece nunca ter havido tantos conflitos, tantas guerras e confrontos quanto hoje; nunca houve tanta fome e exclusão, pelo menos não em números absolutos; nunca tantos migrantes estiveram a vagar pelo mundo sem destino e acolhimento por motivos econômicos, políticos, raciais ou religiosos; nunca houve tamanha devastação da natureza hoje ameaçada de colapso fatal e, sobretudo, nunca houve similar disseminação de tantas e tão letais armas capazes não apenas de destruir vidas, mas de destruir, de um golpe, a humanidade como um todo.

$\bigcirc$ que importa aqui é destacar a soberania, o domínio do sistema econômico sobre os rumos não só da sociedade de modo geral, mas de cada indivíduo em particular. Isso ocorre (e só pode ocorrer) na medida em que o processo formativo se submete aos ditames sistêmicos do capitalismo neoliberal. Para explicar essa situação, é oportuno comentar alguns conceitos que, de alguma forma, marcam essa relação entre o ser humano e o sistema, como expressão de uma nova forma de violência. São os conceitos de uniformização, consumo, estraneidade, homogeinização e insaciabilidade.

\section{II}

É a violência, denunciada por Adorno e Horkheimer (1985) como indústria cultural que destrói a aura, a originalidade, a diversidade de expressão artística, eliminando seu dizer, seu indagar, sua palavra, deixando tudo uniformizado. Nas palavras desses autores, "a cultura contemporânea confere a tudo um ar de semelhança [...] [simulando] perpetuar o indivíduo como se ele fosse independente, submetem-no ainda mais profundamente a seu adversário, o poder absoluto do capital" (ADORNO; HORKHEIMER, 1985, p. 113). Aindústria cultural comete uma das mais destrutivas formas de violência contra o ser humano, que é a violência da uniformização, da distração, da despolitização. Os homens uniformizados são manipuláveis no atacado, todos juntos como massa ou gado, conforme se expressam Adorno e Horkheimer (1985, p. 119): 
a violência da sociedade industrial instalou-se nos homens de uma vez por todas. Os produtos da indústria cultural podem ter a certeza de que, até os distraídos, vão consumi-los abertamente. Cada qual é um modelo da gigantesca maquinaria econômica que, desde o início, não dá folga a ninguém, tanto no trabalho quanto no descanso [...]

A indústria cultural exerce violência pela produção de necessidades que, internalizadas, violentam o ser humano, transformando-o em escravo de seus desejos, artificialmente produzidos para a realização de objetivos econômico-sistêmicos. Ainda segundo os mesmos autores, "a indústria cultural realizou maldosamente o homem como ser genérico. Cada um é tão somente aquilo mediante o que pode substituir todos os outros: ele é fungível, um mero exemplar" (ADORNO; HORKHEIMER, 1985, p. 136). Perdendo, portanto, sua unicidade e sua identidade, o homem não se dá conta da violência que o reduz à sua própria nulidade homogeneizada. Lembremos que as palavras de Adorno e Horkheimer foram escritas em meados da década de 1940. Eram apenas os prenúncios da revolução digital que haveria de explodir a partir das décadas de 1980 e 1990 do século passado, para alcançar níveis que hoje ultrapassam os limites da imaginação.

Os novos meios rompem e ultrapassam quaisquer limites, favorecendo a violência da intimidade. As nossas vidas são espionadas, não apenas com o uso dos meios de controle, mas como função até mesmo do próprio Estado que, segundo a imagem de Bentham, torna-se cada vez mais panóptico e invasivo. Nas palavras de Canclini (2016, p. 68), vivemos "a transparência de nossas vidas espionadas e armazenadas nos bancos de dados da vigilância." É a homogeneização que suprime a identidade que transforma as pessoas em cifras, códigos e números, registrados e à disposição de empresas, de bancos, da justiça e do Estado.

filósofo argentino Nestor Garcia Canclini (2016) criou o novo conceito de estraneidade. Segundo o autor, vivemos a estraneidade violenta de habitar um mundo de teclas, ícones, somas, valores, investimentos, mercado. Os que não se ajustam a isso são estranhos. A violência tornou-se inerente à cultura do capitalismo, da exploração e da exclusão. Vivemos o mundo violento 
do desemprego, das privações, das migrações, em função da estraneidade, do desajuste. Milhões de pessoas são violentamente arrancadas de suas casas, de suas famílias, de suas cidades e países. São expulsos para lugares onde não podem falar sua língua, cultivar seus costumes, comunicar-se com seus deuses. Metade ou quase metade da população mundial é excluída do sistema econômico capitalista neoliberal. Milhões andam vagando pelo mundo, perdidos nos Mediterrâneos do nada e do ninguém; milhões vivem nas periferias do sistema, nas favelas, nos slums, sem abrigo, sem comida, sem direitos, sem língua.

Ora, a língua é a casa, o óikos de cada um. Sabemos que somos seres humanos porque somos seres capazes de elaborar e de sempre continuar elaborando conceitos constituintes da linguagem essencial ao ser humano como meio e suporte do ser, da identidade, da autocompreensão. Privar alguém da linguagem é uma das mais duras e radicais violências que se pode cometer e experimentar. As pessoas falam e têm língua, mas já não falam porque não aprenderam a linguagem do sistema. Essas pessoas não podem aproveitar seu capital educativo, viver sua cultura e, por isso, serão para sempre estranhas, diferentes e indesejadas. É o que se pode chamar de violência da estraneidade que não afeta apenas os migrantes. Há também os estranhos em sua própria sociedade: índios, negros, pobres, desempregados que são violentados em seus direitos nos seus próprios países por não se ajustarem ao sistema, por não atenderem aos interesses do sistema ou, simplesmente, por serem excedentes ao quantum do sistema.

Algo semelhante ocorre com os que se criaram num sistema analógico e agora não conseguem se adaptar ao sistema digital. Nativos desse mundo digital são apenas as crianças e os jovens formados no mundo da internet e, dentre estes, somente aqueles que têm acesso aos recursos eletrônicos. De fato, o mundo digitalizado e virtualizado que comanda o sistema e a vida é inacessível para a maior parte da população. Mas mesmo os que têm acesso, mas não dominam seus códigos, são afetados, conduzidos e induzidos a assumir posturas e práticas sem se darem conta de porquê o estão fazendo. Transformam-se, como anteciparam Adorno e Horkheimer (1985), em rebanho de pessoas sem identidade. 
Segundo alerta Canclini, parece certo que, se não conseguirmos mudar a realidade de maneira radical, precisamos, pelo menos, buscar uma organização político-econômica de rosto mais humano. Precisamos mudar nossa maneira habitual de pensar, eliminando o viés territorial, o viés possessivo, agressivo e consumista. $\bigcirc$ consumismo é hoje o núcleo da mais profunda contradição sistêmica e antropológica. De um lado, o poder de consumo é o critério de avaliação do nível de integração social, de igualdade de direitos, de desenvolvimento político e econômico, de democracia e de justiça social. De outro, o poder de consumo é critério de distinção, de status, de superioridade.

Efetivamente, no primeiro sentido, consumo significa ter acesso aos bens produzidos pelo trabalho como alimento, moradia, emprego e lazer. No segundo sentido, porém, o consumismo é um dos mais nefastos efeitos do capitalismo neoliberal. Nessa perspectiva, representa não apenas o consumo de produtos necessários à boa vida, mas a sagração do consumo como sentido e ideal de vida com todos os efeitos danosos que essa atitude implica. A forma mais radical e agressiva de consumismo é o consumo antropofágico do próprio ser humano, do outro, do seu tempo, de sua liberdade, de sua autonomia. Visto de perto, trata-se de uma moderna forma, suave e sutil, de canibalismo, ou seja, de consumo do outro, que representa a mais brutal forma de violência. E hoje 'alcançamos' o patamar da autofagia. $\bigcirc$ filósofo sul-coreano Byung-Chul Han (2017, p. 29-30), radicado na Alemanha, escreve que o sujeito de desempenho está livre da instância externa de
domínio que o obriga a trabalhar ou que podia explorá-lo.
É senhor e soberano de si mesmo. Assim não está submisso
a ninguém ou está submisso apenas a si mesmo. É nisso
que ele se distingue do sujeito de obediência. A queda da
instância dominadora não leva à liberdade. Ao contrário,
faz com que liberdade e coação coincidam. [...] $\bigcirc$ exces-
so de trabalho agudiza-se numa autoexploração. Essa é
mais eficiente que a exploração do outro, pois caminha de
mãos dadas como sentimento de liberdade. $\bigcirc$ explorador
é ao mesmo tempo o explorado. Agressor e vítima não po-
dem ser mais distinguidos.

Consumo se reporta a outro fenômeno que só agora começa a chamar a atenção de economistas, filósofos, antropólogos e que deveria ser 
preocupação de todos os educadores: a insaciabilidade. Segundo Skidelski e Skidelski (2017, p. 15), no recém-lançado livro Quanto é suficiente, a insaciabilidade é a "predisposição psicológica que nos impede, como indivíduos e sociedade, de dizer 'já é suficiente'." Segundo os autores,

os marxistas insistem que esta característica econômica é uma criação do capitalismo e desaparecerá quando este for abolido. Os cristãos argumentam que é produto do pecado original. Nossa visão é que a insaciabilidade tem raízes na própria natureza humana - uma predisposição para comparar a nossa sorte com a de nossos semelhantes e desejá-la -, mas foi intensificada ao máximo pelo capitalismo, que fez dela a base psicológica de toda uma CIVILIZAÇÃO. (SKIDELSKI; SKIDELSKI, 2017, p. 15).

$\bigcirc$ economista John Maynard Keynes (1963), num artigo publicado pela primeira vez em 1930, Economic Possibilities for our grandchildren, defendeu o ponto de vista de que o progresso tecnológico aumentaria a produção de bens por hora trabalhada para satisfazer suas necessidades até o ponto em que não necessitasse mais trabalhar. Como se sabe, esse prognóstico de um autocontrole do consumismo não só não aconteceu, senão que o consumo se tornou o ideal de vida e de felicidade das pessoas. $\bigcirc$ interessante no artigo de Keynes é a pergunta subjacente: para que serve a riqueza? Essa pergunta supõe que o dinheiro não deve ser um fim em si mesmo. $\bigcirc$ dinheiro, assim se supõe, serve para ser usado, e essa atividade com o tempo perderia a motivação e a aprovação social, causando a auto extinção do capitalismo após sua realização. $\bigcirc$ que ocorreu de fato foi o contrário.

Keynes falhou no seu diagnóstico porque não fez distinção entre 'desejos' e 'necessidades'. Julgava que se as necessidades que são finitas estivessem satisfeitas, os desejos diminuiriam. Ocorre que os desejos, por serem puramente psíquicos, são infinitos. Também não entrou no cálculo de Keynes a possibilidade de se criar artificialmente sempre novas necessidades, embora estas devessem estar associadas a algum objetivo desejável. Além disso, é preciso considerar a dupla face do desejo humano: o lado individual ou isolado e o lado social, associado aos desejos de outros. Os desejos não se explicam apenas pelo viés individualista. Os desejos de consumo obedecem, 
em grande medida, ao status social que é sempre comparativo. Nesse sentido, a insaciabilidade é gerada socialmente. Um dos mecanismos para gerar desejos e necessidades artificiais é a publicidade, na expressão de um ex-diretor da General Motors, como 'a criação organizada de insatisfação'.

Esses breves comentários de alguns conceitos revelam a mudança progressiva das relações humanas e a transformação das práticas quotidianas introduzidas pela nova economia, gerando tensões múltiplas e impulsos disjuntivos que fomentaram a articulação, mas também a separação das diferentes esferas da vida. Segundo Dardot e Laval (2016, p. 323), "o homem moderno se dividiu em dois: o cidadão dotado de direitos inalienáveis e o homem econômico guiado por seus interesses, o homem como 'fim' e o homem como 'instrumento'."

A história da modernidade promoveu um desiquilíbrio entre esses dois polos a favor do segundo. A relação mercantil engendrou no sujeito primazias com efeito disjuntivo de enorme significado para a sua integridade. Tornou-se prioritário o dispositivo da 'eficácia' e do 'desempenho', ou seja, da utilidade sistêmica do ser humano, elevada ao sentido mais alto e finalidade última do processo educacional da mente e do controle do corpo. De acordo com Dardot e Laval (2016, p. 324), "foi este dispositivo da eficácia que forneceu à atividade econômica os recursos necessários, foi ele que produziu incessantemente as mentes e os corpos aptos a funcionar no grande circuito da produção e do consumo."

Dessa estratégia de eficácia fez e faz parte tanto o adestramento dos corpos quanto a gestão das mentes. A disciplinarização dos corpos tem como efeito desejado o funcionamento da subjetividade, como mostra com clareza o modelo panóptico proposto por Bentham, para o controle dos corpos e das mentes. A observação e o controle incessante dos corpos têm como finalidade a moldagem subjetiva. Com essa 'reeducação' do pensamento, o sujeito internaliza a vontade externa que o conduz. Sem se dar conta, o sujeito assume como sua a vontade externa que o domina e instrumentaliza. Nos termos de Laval e Dardot (2016, p. 325): 
Postular a liberdade de escolha, suscitar e constituir na prática essa liberdade pressupõe que os sujeitos sejam conduzidos por uma 'mão invisível' a fazer as escolhas que serão proveitosas a todos e a cada um [...] [como] uma máquina que funciona idealmente por si só e encontra em cada sujeito uma engrenagem pronta a responder às necessidades de arranjo do conjunto.

A polarização social e a concorrência em todos os níveis minam a solidariedade e a capacidade coletiva (DARDOT; LAVAL, 1916, p. 9). Surge um cenário em que as gerações mais velhas vestem seus trajes ideológicos, já surrados e démodés, mas no fundo se ajustam, resignados ao sistema para o qual não veem alternativa viável, e os jovens se tornam revolucionários pro tempore até o momento em que lhes ocorra igual sina, ou seja, até o sistema lhes revelar suas exigências inexcusáveis e incontornáveis como condição de uma vida economicamente digna e confortável. Sem alternativa e integrados ao sistema, as novas gerações lembram como memórias de juventude a ontologia do materialismo histórico no qual haviam um dia apostado todas as suas fichas de um mundo melhor, mais democrático e justo.

Apesar de todas as consequências catastróficas do neoliberalismo econômico, esse sistema não encontra resistências capazes de lhe opor enfrentamento com perspectivas de sucesso. Segundo Dardot e Laval (2016, p. 160), "com o neoliberalismo, o que está em jogo não é nada mais nada menos que a forma de nossa existência, isto é, a forma como somos levados a nos comportar, a nos relacionar com os outros e com nós mesmos." Nesse sentido, o neoliberalismo, muito mais que um mero sistema econômico, de certo modo externo a nós mesmos, é um sistema que nos impõe formas de comportamento e de relacionamento social, cujo eixo movente é a competição generalizada, a luta econômica de uns contra os outros, da qual sairão vitoriosos apenas os mais competentes e adaptados. Embora a ideologia assegure que essa luta é sempre aberta e decidida pela competência, está fora de qualquer dúvida que as condições econômicas decidem sobre o destino da maioria, seja para o domínio, seja para a servidão.

A tese de Dardot e Laval (2016, p. 17) refere-se à ideia de que o neoliberalismo, mais que uma ideologia ou uma política econômica, é uma 
forma de racionalidade que estrutura as normas de pensar e de agir das pessoas: "A racionalidade neoliberal tem como característica principal a generalização da concorrência como norma de conduta e da empresa como modelo de subjetivação." É um novo modelo de governo dos homens, exercido seja do exterior pelo sistema, seja do interior enquanto assumido pelo indivíduo, à luz dos princípios universais da concorrência e da utilidade. $\bigcirc$ neoliberalismo define novas normas de vida para as sociedades ocidentais e todas as sociedades que seguem ou pretendem seguir o caminho da modernidade. Como dizem os mesmos autores em sua obra mais recente que leva o título Comum (2017),

o capitalismo continua a desenvolver sua lógica implacável, mesmo demonstrando dia após dia a temível incapacidade de dar a mínima solução às crises e aos desastres que ele próprio engendra. Parece até estender seu domínio sobre a sociedade à medida que desfia suas consequências.

O desejo da empresa é internalizado pelo sujeito como o seu próprio desejo. Esse processo de internalização é levado a termo mediante estratégias suaves e indiretas de propaganda e marketing que enaltecem as vantagens individuais de participação, consumo e felicidade. $\bigcirc$ núcleo desses processos é induzir as pessoas a assumir, elas mesmas e consigo mesmas, a função de protagonistas desse processo. Trata-se da internalização/subjetivação dos interesses do sistema pelo sujeito como se fossem genuínos interesses seus, interesses inerentes ao seu próprio desempenho. Nesses termos, Han (1917, p. 29) considera que

O sujeito de desempenho está livre da instância externa de domínio que o obriga a trabalhar ou que poderia explorá-lo. É superior e soberano de si mesmo. Assim não está submisso a ninguém ou está submisso apenas a si mesmo. É nisso que ele se distingue do sujeito de obediência. A queda da instância dominadora não leva à liberdade. Ao contrário, faz com que liberdade e coação coincidam. 
Assim, o homem soberano, imaginado por Nietzsche, acabou submetido ao sistema. Um ser melancólico e depressivo transformado em massa, como lembram Adorno e Horkheimer.

\section{III}

O dinheiro, que era meio, transformou-se em fim. Skidelski e Skidelski (2017, p. 24) afirmam que "os economistas [...] veem os seres humanos como burros de carga que precisam do estímulo de um carroceiro ou de um chicote para seguir em frente." A educação é um dos mecanismos usados para o controle das mentes e dos corpos que institucionaliza o novo ideal de homem, a um só tempo; o indivíduo parte da engrenagem pronta a responder às exigências do sistema de produção/consumo e aspiração de autonomia/liberdade. $\bigcirc$ momento neoliberal produz hoje um novo sujeito, denominado por Dardot e Laval (2016, p. 327) como sujeito empresarial ou neosujeito, ou seja, um "sujeito ativo que deve participar inteiramente, engajar-se plenamente, entregar-se por completo à sua atividade profissional."

Interessa destacar aqui a relação intrínseca entre o sistema econômico/neoliberal/capitalista e a prática da violência, e derivar dessa constatação a tese de que a educação, enquanto processo de integração dos indivíduos no sistema, está fortemente atrelada à ideia de preparo dos jovens não só para o mundo violento, mas também à habilitação dos jovens para o manejo e o exercício da violência no interior do sistema como estratégia de sobrevivência e afirmação pessoal.

Nesses termos, importa chamar a atenção para o processo de naturalização da violência como parte da sobrevivência do indivíduo e do próprio sistema. Em outras palavras, torna-se cada vez mais evidente que a educação assume como encargo, pelo menos parcial, qualificar os jovens para o manejo da violência como estratégia de sucesso. Como se percebe, trata-se de uma tese provocadora que visa estimular o debate sobre educação e violência 
desde a perspectiva da educação, não apenas como vítima da violência, mas da educação como promotora de violência.

A educação de hoje tende, pelo menos em grande medida, a transformar-se em um mecanismo de enquadramento sistêmico do ser humano, assumindo, consciente ou inconscientemente, a tarefa de habilitar os indivíduos para o exercício da violência como condição de seu sucesso. As práticas pedagógicas tendem a transformar-se em estratégias de adaptação e integração dos jovens no sistema econômico/financeiro cujo objetivo maior é atender aos interesses do capital.

Trata-se de defender a urgência, sobretudo em termos de filosofia e teoria educacionais, de pensar, ou melhor, de repensar o modelo educacional no contexto do capitalismo neoliberal. Uma tarefa complexa e dilemática porque envolve, de um lado, a tarefa formativa, humanista da educação e, de outro, a necessidade incontornável de preparar as novas gerações para o mundo real, com todos os traços anti-humanistas que lhe são inerentes. Ideologia humanista e exigências realistas se encontram em conflito paralisante. Esse é o embate teórico/prático, ideológico/pragmático que envolve a discussão sobre as reformas educacionais, atualmente em curso ou ainda em tramitação no Congresso e no Senado. $\bigcirc$ que está em jogo é a transformação/superação do sistema econômico e a inauguração de um novo humanismo ou a aceitação da incontornável realidade econômica neoliberal e a adequação do ser humano às suas exigências.

A escola se tornou um espaço em que se realiza uma das marcas essenciais do capitalismo assim descrita por Skidelsky e Skidelski (2017): "[... a combinação entre igualdade social e desigualdade de renda tornou-se norma do capitalismo, criando uma situação em que cada membro da sociedade está, de alguma maneira, competindo com o outro." O ser humano se transforma, ele mesmo, em uma empresa de modo que seu fracasso é seu fracasso enquanto empresa. Dardot e Laval (2016, p. 327) descrevem essa realidade nos seguintes termos:

Trata-se agora de governar um ser cuja subjetividade deve estar inteiramente envolvida na atividade que se exige que 
ele cumpra. Para isso, deve-se reconhecer nele a parte irredutível do desejo que o constitui. As grandes proclamações a respeito da importância do "fator humano" que pululam na literatura da neogestão, devem ser lidas à luz de um novo tipo de poder; não se trata mais de reconhecer que o homem no trabalho continua a ser um homem, que ele nunca se reduz ao status de objeto passivo; trata-se de ver nele o sujeito ativo que deve participar inteiramente, engajar-se plenamente, entregar-se por completo à sua atividade profissional.

É para esse cenário que a educação deve preparar os jovens de hoje. Ela deve tratar da modelagem dos indivíduos para que se tornem aptos a suportar as condições que lhe são impostas. Nas palavras de Baudrillard (2007, p. 15-19), "nos tornamos funcionais. [...] Na fenomenologia do consumo chegamos ao ponto em que o 'consumo' invade toda a vida." E na medida em que o sujeito se torna empresa de si mesmo que se oferece no mercado, o próprio ser humano se torna objeto de consumo por parte do sistema. $\mathrm{Na}$ contabilidade da vida contemporânea somente contam os fatores viáveis e mensuráveis, segundo os critérios da racionalidade econômica.

A educação, de modo geral, parece se submeter, do ponto de vista da formação, aos mesmos critérios da racionalidade econômica que dominam as relações humanas. É para esse cenário que a educação deve preparar os jovens de hoje. Ela deve cuidar da modelagem dos indivíduos ao sistema econômico, tornando-os os mais eficazes possível, dispostos à aprendizagem contínua, extremamente flexíveis em razão das permanentes mudanças impostas pelo mercado. $\bigcirc$ 'sujeito' do futuro deve ser "especialista de si mesmo, empregador de si mesmo, inventor de si mesmo, empreendedor de si mesmo: a racionalidade neoliberal impele o eu a agir sobre si mesmo para fortalecer-se e, assim, sobreviver na competição." (DARDOT; LAVAL, 2016, p. 331).

Surge, assim, o modelo de uma nova ética, no qual a empresa se torna não apenas o modelo/ideal ao qual o sujeito deve se adaptar enquanto profissional, mas também uma postura de vida a ser valorizada e assumida pela família e pela escola no processo formativo. Desde pequenas as pessoas devem ser induzidas a entender-se como microempresas nas quais é preciso investir, de modo a aumentar seu valor de mercado, visto que, no contexto dessa nova 
realidade, o indivíduo é avaliado pelo seu valor de mercado. A educação passa a ser uma parte importante dessa gestão do sujeito/empresa, importando cada vez menos o desenvolvimento integral, ético/estético, da pessoa. $\bigcirc$ objetivo de vida é competência e a competitividade, visando à valorização da pessoa enquanto 'capital humano'. Assim, segundo formulam Dardot e Laval (2016, p. 326), "o momento neoliberal caracteriza-se por uma homogeneização do discurso do homem em torno da figura da empresa." Importante observar que já não se trata de coerção e adestramento dos corpos e do espírito como ocorria nas antigas disciplinas, mas de um governo da subjetividade pela imersão da pessoa no sistema econômico. Ocorre uma identificação de ideais e objetivos entre sujeito e sistema, de modo que os interesses sistêmicos e subjetivos coincidem na modelagem do ser humano como empresa.

A ética empresarial é a ética do nosso tempo, cuja dinâmica tem como polo a identificação entre as aspirações individuais e as expectativas do mercado. A grande questão ética é a junção das aspirações do indivíduo e da empresa. $\bigcirc$ preço a pagar por essa coincidência entre projeto econômico e projeto humano é a anulação do sujeito, reduzindo-o à sua competência produtiva plenamente submissa às leis do mercado. Essa é a nova versão da epimeleia heautou (do cuidado de si) da qual nos fala Foucault na hermenêutica do sujeito. Hoje o cuidado de si consiste em gerir um portfólio do capital, das vantagens, experiências, qualificações, relacionamentos, competências de si mesmo para tornar o indivíduo atraente e útil aos objetivos do mercado.

Talvez pareça exagerado falar tanto de instrumentalização do sujeito, uma vez que hoje se debate muito a respeito dos aspectos psicológicos, éticos e humanísticos em diversos âmbitos sociais, como, por exemplo, na mídia, nos meios políticos, na escola, na universidade. No entanto, é importante estar atento às intenções subjacentes a essas discussões. É preciso não esquecer que esses debates sobre as problemáticas psicológicas e éticas buscam menos a autonomia, a liberdade e a autodeterminação do sujeito, mas "trata-se de construir, com o auxílio da psicologia e da ética, técnicas de governo de si que são parte interessada do governo e da empresa." (DARDOT; LAVAL, 2016, p. 344). Essa realidade do mundo, da empresa, do econômico é o lado fixo (embora sempre mutante) da relação entre o indivíduo e o mundo da economia 
e do Estado. E digo do Estado porque este, hoje, está sujeito, atrelado aos interesses da economia, como percebemos inequivocamente no cenário mundial e brasileiro. Não é o mundo e a economia que levam em consideração o indivíduo, mas é o indivíduo que deve acompanhar e se adaptar às exigências do sistema. $\bigcirc$ cuidado de si e os rumos do mundo econômico entram numa relação de promiscuidade fatal para o sujeito, sua independência, autonomia e liberdade. Elimina-se, no dizer de Adorno e Horkheimer (1985, p. 27), o incomensurável na medida em que os homens são forçados à conformidade. 0 destino do indivíduo passa a ligar-se inextrincavelmente ao sistema, cabendo a este último determinar sua identidade e seus rumos.

Isso implica a transformação do sujeito em indivíduo transacional e não mais relacional. Essa mudança interfere de maneira profunda no ser humano enquanto sujeito ético a ser respeitado enquanto tal com direito à integração relacional com os outros. Sua dignidade e reconhecimento não dependem mais de posturas humanas de responsabilidade e respeito no tratamento com os outros, mas do desempenho técnico/profissional, de sua eficácia no mundo concorrencial. $\bigcirc$ sujeito deve funcionar como peça de uma engrenagem econômica, cujos mecanismos ele não conhece e muito menos domina. Esta, repito, é a nova linguagem da educação, por isso, como educadores, cabe-nos perguntar o que significa, em termos teóricos e práticos, este, assim designado por Adorno e Horkheimer (1985), triunfo da igualdade repressiva.

\section{CONCLUSÃO}

Tentei argumentar que estamos vivendo hoje uma supremacia do sistema econômico neoliberal sobre os ideais tradicionais, sobretudo modernos, de autonomia, liberdade e autodeterminação do sujeito. Nesse contexto, o propósito da educação de promover a capacidade reflexiva com vistas à formação de um adulto autônomo, um cidadão capaz de decidir por critérios próprios, é substituída pela capacidade de alcançar identidade social, subjetivamente indeterminada, mas sistemicamente sintonizada. A educação, 
entendida como processo de socialização e integração social, de aceitação ou de rejeição consciente do sistema sociocultural, transformou-se em processo de submissão sem alternativa ao sistema. A crença moderna na capacidade racional do indivíduo de governar sua própria vida, independente dos condicionantes sistêmicos e mesmo dos avanços da ciência e tecnologia, alcança seus limites no contexto da tecnologia social e de suas estratégias de intervenção que limitam e interferem, cada vez mais, na autonomia do ser humano no que diz respeito à construção de sua subjetividade e de sua identidade.

Subjaz à minha argumentação uma postura realista, reconhecendo que o ser humano alcançou um momento crucial de perda de autonomia e liberdade que nunca foi plena e absoluta, sempre permaneceu como horizonte de sentido da vida humana. Se fui incisivo na apresentação deste argumento, em nenhum momento foi meu intuito provocar desânimo e resignação; ao contrário, julgo fundamental para a educação de hoje tomar consciência dessa realidade, acordar do sonho de um pedagogismo romântico para a urgência de enfrentar o totalitarismo sistêmico que ameaça nosso futuro.

\section{REFERÊNCIAS}

ADORNO, T.; HORKHEIMER, M. Dialética do esclarecimento. Rio de Janeiro: Zahar, 1985.

ARISTÓTELES. A política. São Paulo: Lafonte, 2012.

BAUDRILLARD, J. A sociedade de consumo. Lisboa: Edições 70, 2007.

DARDOT, P.; LAVAL, C. A nova razão do mundo: ensaio sobre a sociedade neoliberal. Tradução Mariana Echalar. São Paulo: Boitempo, 2016.

DARDOT, P.; LAVAL, C. Comum: ensaio sobre a revolução no século XXI. Tradução Mariana Echalar. São Paulo: Boitempo, 2017.

CANCLNI, N. G. O mundo inteiro como lugar estranho. São Paulo: EDUSP, 2016.

GINDSBURG, C. Medo, reverência e terror. São Paulo: Companhia das Letras, 2014. 
HAN, B.-C. Sociedade do cansaço. Tradução Enio Paulo Giachini. Petrópolis: Vozes, 2017.

HOBBES, T. Leviatã: ou matéria, forma e poder de um Estado Eclesiástico e Civil. São Paulo: Martin Claret, 2006.

KANT, I. Crítica da faculdade do juízo. 2. ed. Rio de Janeiro: Forense Universitária, 2008.

KANT, I. Crítica da razão prática. São Paulo: Martin Fontes, 1984.

KANT, I. Crítica da razão pura. Lisboa: Fundação Calouste Gulbenkian, 1985.

KEYNES, J. M. Essays in persuasion. New York: W.W. Norton \& Co: 1963.

NIETZSCHE, F. Humano, demasiadamente humano: um livro para espíritos livres. São Paulo: Companhia da Letras, 2005.

ROUSSEAU, J. J. Discurso sobre a origem e os fundamentos da igualdade entre os homens. São Paulo: Ática, 1989.

SHERMER, M. The moral Arc, how Science and reason lead humanity toward truth, justive and freedom. New York: Henry Holt and Company, 2015.

SKIDELSKI, R.; SKIDELSKI, E. Quanto é suficiente? Rio de Janeiro: Civilização Brasileira, 2017.

Recebido em:: 02 de abril de 2018 Aceito em:: 21 de junho de 2018

Endereço para correspondência: Rodovia Raposo Tavares, Km 92,5, Vila Artura, caixa postal 1 1, 18023-000, Sorocaba, São Paulo, Brasil; pedro.goergen@ hotmail.com 
